\title{
A Qualitative Study of Friendship in Patients with Anorexia Nervosa and Possible Autism Spectrum Disorder
}

\author{
Eli Doris ${ }^{1,2 *}$, Heather Westwood ${ }^{*}$, William Mandy3 ${ }^{3}$ Kate Tchanturia ${ }^{1,2,4 \#}$ \\ ${ }^{1}$ Department of Psychological Medicine, Institute of Psychiatry, King's College London, London, UK \\ ${ }^{2}$ Eating Disorders Adult National Service, South London and Maudsley NHS Foundation Trust, London, UK \\ ${ }^{3}$ Research Department of Clinical, Educational and Health Psychology, University College London, London, UK \\ ${ }^{4}$ Illia State University, Tbilisi, Georgia \\ Email: "kate.tchanturia@kcl.ac.uk
}

Received 12 June 2014; revised 8 July 2014; accepted 2 August 2014

Copyright (C) 2014 by authors and Scientific Research Publishing Inc.

This work is licensed under the Creative Commons Attribution International License (CC BY).

http://creativecommons.org/licenses/by/4.0/

c) (i) Open Access

\begin{abstract}
Difficulties in friendships have been reported both in people with Autism Spectrum Disorder (ASD) and in individuals with Anorexia Nervosa (AN). This small-scale qualitative study aimed to evaluate the friendship experiences of seven patients with AN who presented with possible ASD traits; to determine whether their experiences were reflective of those found in people with ASD, and whether any difficulties were present before the onset of their eating disorder. Participants were interviewed using the ADOS-G and the interviews were transcribed and analysed. Four principle themes emerged from the thematic analysis: limited social network, lack of contact or communication, difficulty understanding the concept of friendship, and focus of attention away from the self; which could not be explained by the state of starvation alone. The evidence presented here not only reflects the friendship experiences of individuals with AN as documented in the literature, but also the friendship difficulties which have been observed in people with ASD without a comorbid eating disorder. The findings provide evidence that friendship difficulties experienced by people with AN precede the onset of the eating disorder and therefore offer support for the idea of a shared phenotype between AN and ASD. This study also highlights the need to address friendship difficulties in treatment interventions for AN in order to promote recovery. Further research is warranted to better explore the friendship similarities between people with AN and ASD, and to develop friendship focused interventions for patients with $\mathrm{AN}$.
\end{abstract}

\footnotetext{
*The two authors contributed equally to this study.

"Corresponding author.
}

How to cite this paper: Doris, E., Westwood, H., Mandy, W., \& Tchanturia, K. (2014). A Qualitative Study of Friendship in Patients with Anorexia Nervosa and Possible Autism Spectrum Disorder. Psychology, 5, 1338-1349. 


\section{Keywords}

\section{Anorexia Nervosa, Eating Disorders, Autism Spectrum Disorder, Friendship, Qualitative Study}

\section{Introduction}

Social functioning is one of the most important aspects of human life, and friendship is an important facet of social functioning. Spending time with other people is vital for human beings and social deprivation/isolation naturally leads to poor quality of life (Wilkinson \& Marmot, 2003). Research has shown that friends provide humans with support and companionship, but also a sense of honour, inspiration, and improved physical and mental well-being (Flora, 2013).

Abnormality in social interaction and communication development is one of the main features of Autism Spectrum Disorder (ASD; DSM-5; American Psychiatric Association, 2013). Autism is well researched in terms of friendships and relationships (e.g. Baron-Cohen \& Wheelwright, 2003; Orsmond, Krauss, \& Seltzer, 2004). Notably, Baron-Cohen and Wheelwright developed the Friendship Questionnaire (FQ; 2003), on which high scores indicate the enjoyment of close friendships and the attachment of importance to these friendships. The results of the study showed that adults with a diagnosis of Asperger syndrome or high-functioning autism scored significantly lower on the FQ than controls from the general population; a finding concordant with the autism diagnostic criterion of abnormality in social interaction and communication development.

Bauminger and Shulman (2003) found that children with ASD most frequently engaged in passive activities such as watching television, which is concordant with later research showing that children with ASD were more likely to engage in parallel as opposed to interactive play (Bauminger et al., 2008). Interestingly, Kuo, Orsmond, Cohn and Coster (2011) found that while adolescent males with ASD favoured passive activities over direct social interactions, adolescent females with ASD demonstrated the opposite preference, favouring having conversations with their friends over other activities; a finding which is consistent with the activity preference patterns of typically developing adolescents (Larson \& Verma, 1999).

Bauminger and Kasari (2000) found that despite the fact that children with ASD reported having at least one friend, these children perceived less closeness and intimacy in their friendships than did typically developing children. The children with ASD also displayed a poorer understanding of the relationship between loneliness and friendship, although they did report feeling lonely. In a qualitative study, Carrington, Templeton and Papinczak (2003) explored the perceptions of friendships in adolescents with Asperger Syndrome. It was discovered that, in general, the individuals interviewed found it difficult to talk in depth about their experiences of friendship and in particular they found it difficult to describe what a friend was; furthermore, the authors did not believe that the individuals' interviews reflected a true understanding of the nature of their friendships.

Difficulties with friendship have also been observed in individuals suffering from an eating disorder (ED), in particular Anorexia Nervosa (AN). Krug et al. (2012) found that children with an ED took part in more solitary activities than did non-eating disordered controls and that this behaviour continued into adulthood. It has also been noted that women who go on to develop AN are more likely to report few or no childhood friends (Fairburn, Cooper, Doll, \& Welch, 1999). Tiller and colleagues (1997) found that individuals with an ED have smaller social networks than do non-eating disordered controls. This may be particularly true for patients who have been hospitalised due to the severity of their illness, given that these admissions can be lengthy and will inevitably result in a degree of isolation from their lives outside hospital. More recent research has shown that people with AN report high levels of poor social functioning (Tchanturia, Hambrook, Curtis et al., 2013), social anhedonia (Tchanturia, Davies, Harrison, Fox et al., 2012; Harrison, Mountford, \& Tchanturia, 2014), and lower levels of empathy (Morris, Bramham, Smith, \& Tchanturia, 2014).

Tiller and colleagues (1997) observed that although AN patients reported less actual emotional and practical support than the comparison group, they nevertheless perceived this social support to be adequate and set lower ideals for support than did people without an ED. Despite this, there is a well-documented link between loneliness and ED pathology (Pritchard \& Yalch, 2009), with higher levels of loneliness being associated with higher levels of weight and shape concern as well as body dissatisfaction. During recovery, the presence of moral support and guidance from one's social group becomes a particularly pertinent issue, as effective reintegration into 
the community is largely dependent upon support from one's peers. This conjecture is supported by Harney, Fitzsimmons-Craft, Maldonado and Bardone-Cone (2014), who found that improved perceptions of social support act as a mediating factor in recovery from an ED. However, observations from clinical practice repeatedly show that it is exactly these close, supportive relationships which AN patients lack.

With regard to treatment interventions focusing on the friendship difficulties experienced by AN patients, the available literature is very limited. To the best of our knowledge, only one study has been published in this area within an ED inpatient setting (Davies, 2004). In this case, a group work approach was taken to address friendships in adolescent inpatients with (primarily) AN, focusing on beliefs about friendship, the process of making friends and the development of communication skills. The patients' feedback and case examples were positive, indicating that they found this group to be both useful and valuable. However, the group work tended to focus on rebuilding existing friendships which had been damaged as a result of the individual's eating disorder, rather than on basic social and communication skills which may have been lacking in the first place. Given the importance of friendships in the recovery process and the lack of defined supportive interventions, further research into the development of appropriate therapies which are tailored to these needs is warranted.

Despite friendship difficulties in young people with AN being well documented, the precise nature of the relationship between friendship difficulties and ED behaviours remains unclear: do difficulties in friendship precede the ED, or is it the ED which leads to friendship difficulties? One study which provides some support for the former hypothesis was carried out by Troop and Bifulco (2002), who found that women with a history of AN (binge/purge subtype) reported higher levels of loneliness, shyness and feelings of inferiority during adolescence than did women with no history of an ED; however this difference was not observed when restricting subtypes were compared with individuals who had no ED history. Similarly, another group of researchers found that higher levels of sociotrophy (a personality trait characterised by high levels of dependence and an excessive need to please others) and perceived reductions in social support made unique contributions to eating disturbances six weeks later, among a group of healthy adult females (Jackson, Weiss, Lunquist, \& Soderlind, 2005). An alternative account of the relationship between friendship difficulties and ED behaviours suggests that low self-esteem acts as a mediating factor, such that low self-esteem during childhood predisposes individuals with friendship difficulties to develop an ED later on (Geller, Zaitsoff \& Srikameswaran, 2002).

Another explanation for the friendship difficulties seen in AN comes from Gillberg's hypothesis, which has received growing attention in recent years and suggests that AN in a sub-group of cases might represent a disorder linked to autism (Gillberg, 1985). With regard to friendships, Gillberg and Rastam (1992) found that 32/51 (63\%) adolescent AN cases reported major peer friendship problems from early childhood, while the corresponding number in the comparison group was only 8/51 (16\%); an observation which perhaps echoes the difficulties with social interaction and communication characteristic of autism, and also seems to fit the profile of the ED (and especially AN) patients seen currently in clinical settings. Furthermore, Gillberg and Rastam (1992) observed behavioural patterns such as restricted interests and obsessiveness among their AN patient group which they theorized were indicative of an autistic-like condition. Observations from research and clinical practice are concordant with this finding; a number of systematic reviews and large-sample studies have highlighted that people with AN have difficulties with cognitive flexibility and extreme attention to detail (Tchanturia, Davies, Harrison, Roberts et al., 2012; Lang, Lopez, Stahl, Tchanturia, \& Treasure, 2014; Tchanturia, Lloyd, \& Lang, 2013). Moreover, a recent systematic review of the literature conducted by Huke, Turk, Saedi, Kent and Morgan (2013) found that the prevalence rates of ASD were significantly higher in ED populations than in non-ED control groups.

Overall, the evidence from research into the friendship experiences of people with AN and ASD suggests striking similarities in this domain; however, it remains unclear whether these similarities are due to a shared phenotype or whether the friendship difficulties observed in people with AN have come to resemble those of people with ASD as a result of starvation (Oldershaw, Treasure, Hambrook, Tchanturia, \& Schmidt, 2011). In order to differentiate between stable traits and the state effects of AN, it is necessary to determine whether friendship difficulties pre-date the onset of the ED and whether these difficulties are concordant with those experienced by people with ASD.

The aim of this exploratory qualitative study was to evaluate the friendship experiences of a group of patients with AN who had been referred by ED adult service clinicians for the assessment of their ASD characteristics, using the Autism Diagnostic Observation Schedule-Generic (ADOS-G; Lord et al., 2000). The study also aimed to determine whether these experiences are similar to the friendship difficulties found in people with ASD, as described in the literature, and whether any difficulties described pre-dated the onset of AN. This is a pilot study, 
the findings from which will inform research hypotheses for a larger project.

\section{Method}

\subsection{Participants}

Seven patients from the Eating Disorders Adult National Service at South London and Maudsley NHS Foundation Trust were interviewed. Clinicians in the adult service were asked to refer for a clinical assessment patients who presented with possible ASD traits. Seven patients were referred in a 4 week period, five of these patients were from the inpatient service and two were from outpatients. All seven patients undertook a clinical ASD assessment, which was videotaped. Ethical permission for the study was obtained from the Clinical and Academic Group at the Institute of Psychiatry. The participants were informed that the study would be written up for research purposes, but that they would remain anonymous. All seven participants were adult females with a mean age of 24.8 years and a clinical diagnosis (DSM-5) of AN. Six out of the seven participants were Caucasian and one was of Afro-Caribbean heritage; all seven participants were British.

\subsection{Measures}

The Autism Diagnostic Observation Schedule-Generic (ADOS-G; Lord et al., 2000) is a standardised, semistructured assessment for ASD. It focuses on the domains of social interaction, communication, play and imaginative use of materials. The ADOS-G has four modules, one of which is selected for the participant, dependent upon their expressive language abilities. All participants in the current study were assessed using ADOS module four, which is designed for verbally fluent adolescents and adults. The activities used in this module include: questions on work, school and daily living; telling a story from a book; creating a story; and discussions about relationships, including friendship. The participant's performance on the ADOS is coded according to strictly defined criteria, yielding scores for a range of items relevant to making a diagnosis of ASD. A subset of these items is used in a diagnostic algorithm, although for the purposes of this research the ADOS-G was used not as a diagnostic instrument, but as a means of eliciting qualitative data on participants' friendship experiences, and therefore diagnostic outcomes from the ADOS-G are not considered in this report.

\subsection{Data Collection}

The AQ-10 (Allison, Auyeung, \& Baron-Cohen, 2012) is a 10-item questionnaire which screens for autistic-like traits. A score of 6 or above is deemed a high score, and indicates that a referral for a full diagnostic assessment for ASD should be considered. The AQ-10 is routinely administered to patients as part of the admission process to the Eating Disorders Service. The five inpatients interviewed for this study had completed the AQ-10; however we were not able to obtain AQ-10 measures from the two outpatient participants. The ADOS-G was administered by a clinical psychologist who specialises in autism research and clinical practice, and who is an ADOS trainer (WM). Assessments were recorded using a video camera, with the consent of the participants being interviewed. The socio-emotional questions on the "Friendships" section of the ADOS-G were transcribed into computer files by one of the authors of this paper (ED). Once the final research report was written, the video recordings were destroyed.

\subsection{Data Analysis}

The thematic analysis method described by Braun and Clarke (2006) was utilised to systematically and rigorously explore the findings from the interviews.

All of the interviews were transcribed manually by one researcher (ED) before initially being analysed (coded) individually by two researchers (ED, HW). Once both researchers had come up with a set of codes capturing their initial thoughts and interpretation of the data, the researchers met to agree on a coding system and then re-analysed the data using these codes. The researchers then met again to discuss any discrepancies in how they had interpreted the data before exploring how the codes could be collated into themes. Themes were generated using an inductive approach without trying to fit the data into an existing theoretical framework. Once the themes had been agreed, the dataset was reviewed to check that the themes worked in relation to the codes and dataset. The themes were then named and defined and a thematic map was produced showing the link between the codes and emergent themes (Figure 1). 


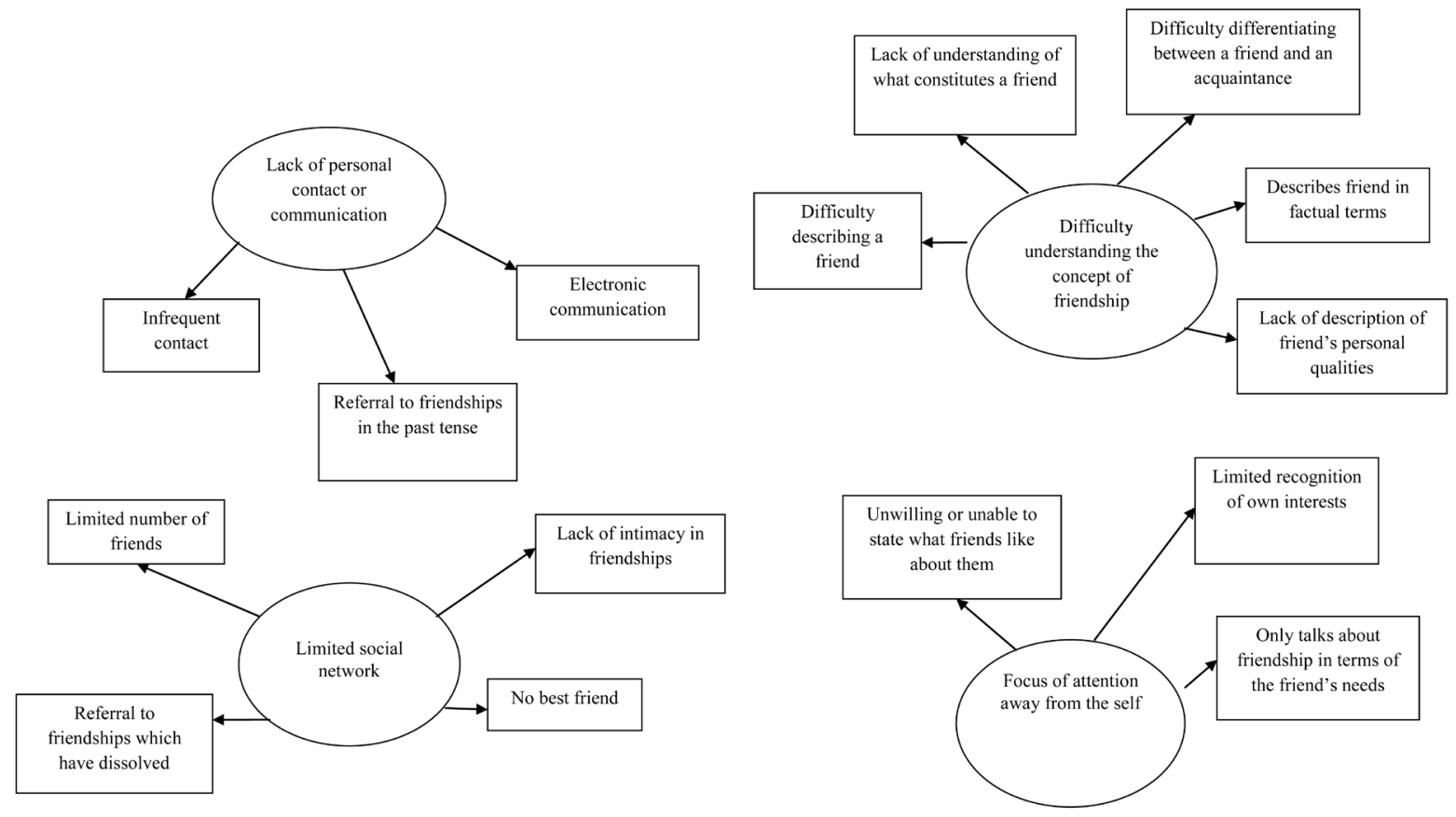

Figure 1. Map of themes and associated codes.

\section{Results}

The emergent themes, along with the frequency of their occurrence among the participants and some examples, are depicted in Table 1.

\subsection{Limited Social Network}

When the study participants were asked if they had some current friendships, all seven individuals demonstrated difficulty in naming even one or two friends, and six participants were either hesitant or paused before answering. Five participants reported that they did not have a best friend, and another reported that she did not have any close friends at all. Furthermore, one participant reported that she would often have been alone without her best (and only) friend whilst at school, and another participant stated that she does not find it easy to form friendships. Finally, given that the participants were being asked to talk about their current friendships, it seems interesting that three out of seven described friendships which had dissolved some time ago, and again this seems indicative of a lack of ongoing close friendships: "She was my best friend as a child but she moved away and we lost touch."

\subsection{Lack of Personal Contact or Communication}

Five out of the seven participants stated that they did not see their friends often, with the frequency varying between once in a while and two-three times per month. Additionally, three participants referred to their current friendships in the past tense, which seems to suggest a dearth of ongoing communication; for example: "It wasn't too often (that I saw her) because we went to different unis.” Moreover, another three participants made reference to electronic means of communicating, such as via text messages, emails and social networking websites; and implied that this would be the preferred means of contact rather than meeting with their friends in person. This final point is illustrated by: “I don’t see her that often...we contact each other quite a lot via email and things.”

\subsection{Difficulty Understanding the Concept of Friendship}

When asked to describe what being a friend means, none of the participants were able to provide a spontaneous answer. They often paused before answering this question, more so than for other questions, and three partici- 
Table 1. Participant responses on the "Friendships" section of the ADOS.

\begin{tabular}{|c|c|c|}
\hline Theme & Frequency & Examples \\
\hline \multirow[t]{4}{*}{ Limited social network } & $100 \%$ & "I only have, I would say, two friends.” \\
\hline & & "I don’t really have a close friendship with any friend." \\
\hline & & “(I’ve) been on my own most of the time.” \\
\hline & & "I don’t think I make friends easily.” \\
\hline \multirow{4}{*}{$\begin{array}{l}\text { Lack of personal } \\
\text { contact or communication }\end{array}$} & $86 \%$ & "I don't see her that often.” \\
\hline & & "We contact each other quite a lot via email and things." \\
\hline & & $\begin{array}{c}\text { "Sometimes if I'm wondering if they're ok I'll probably just give them } \\
\text { a message and see if they'll get back to me." }\end{array}$ \\
\hline & & "When she’s home I usually see her or text her a bit.” \\
\hline \multirow[t]{4}{*}{$\begin{array}{l}\text { Difficulty understanding } \\
\text { the concept of friendship }\end{array}$} & $57 \%$ & $\begin{array}{l}\text { "Umm...I don’t know because I’ve never really had a good friend. } \\
\text { But I think a friend would be someone you could talk to." }\end{array}$ \\
\hline & & "Someone...who's kind and considerate." \\
\hline & & "A friend...maybe you might want to actually ring your friend, once in a while." \\
\hline & & "I don’t know really...just to go out with someone.” \\
\hline \multirow{4}{*}{$\begin{array}{l}\text { Focus of attention } \\
\text { away from the self }\end{array}$} & $43 \%$ & "I don’t really know (what they like about me).” \\
\hline & & "You'd have to ask them (what they like about me)." \\
\hline & & $\begin{array}{l}\text { "(Being a friend) means caring about someone else, } \\
\text { taking an interest in them, wanting to spend time with them.” }\end{array}$ \\
\hline & & "She likes French films so we might go to see a French film." \\
\hline
\end{tabular}

pants were unable to provide any answer at all. Furthermore, four participants were unable to explain the difference between a friend and an acquaintance. When depicting their friends, three participants provided factual information about their friends rather than a portrayal of personal qualities; for example, "She lives round the corner from me.” Finally, two participants described the reason for being friends with someone as being because they were similar to them: "Maybe it's (being friends) because we both have conditions of some sort."

\subsection{Focus of Attention Away from the Self}

Three out of the four participants who were asked what they thought their friends liked about them were either unable or unwilling to provide an answer of any kind. Interestingly, these same participants also either described their friendship in terms of the needs of the other person with no recognition of their own needs: "It means caring about someone else, taking an interest in them, wanting to spend time with them”; or spoke about taking part in shared activities of which the intention seemed to be to please their friend rather than themselves: "We'd maybe visit a London museum because she's quite into that kind of thing.”

\section{Discussion}

The theory of a link between AN and ASD, originally hypothesised by Gillberg (1985), has been supported by a number of research studies demonstrating the difficulties in social functioning experienced by people with AN. Individuals with AN experience high levels of social anhedonia (Tchanturia, Davies, Harrison, Roberts et al., 2012; Tchanturia, Hambrook, Curtis et al., 2013; Harrison et al., 2014); lower emotional intelligence in comparison with IQ and age-matched non-clinical females (Hambrook, Brown, \& Tchanturia, 2012); high scores on self-report ASD measures (Hambrook, Tchanturia, Schmidt, Russell, \& Treasure, 2008; Tchanturia, Smith, Weineck et al., 2013); problems with Theory of Mind (Tchanturia et al., 2004; Russell, Schmidt, Doherty, Young, \& Tchanturia, 2009); lower levels of empathy compared to people recovered from AN and non-ED controls (Morris et al., 2014); as well as poor emotional expressivity (Davies, Schmidt, \& Tchanturia, 2013) and 
regulation (Harrison, Sullivan, Tchanturia, \& Treasure, 2010). The finding that AN patients encountered friendship difficulties prior to the onset of their ED (Fairburn et al., 1999) has highlighted the need for further research in this area. Our small pilot study aimed to explore the friendship experiences of people with AN using a semi-structured clinical interview (ADOS-G).

Of the four themes that emerged during data analysis, limited social network was the most prevalent, apparent in all seven participants. Participants ranged from having no friends at all to being able to name up to three friendships, but then struggled to elaborate on these friendships or discuss them in any detail. These findings are consistent with the literature on ASD which suggests that young people with ASD have fewer friends than typically developing individuals (Bauminger \& Kasari, 2000) and engage in more solitary activities (Bauminger et al., 2008). It is worth noting however, that as the participants were inpatients with severe AN, their social network would likely be affected by their hospital admission; this was mentioned by two participants. However, even when discussing childhood friendships, many of the participants alluded to having had a limited number of friends and commented on spending time alone at school.

As well as being consistent with findings from research into the friendship patterns of children with ASD, our observation that people with AN have a limited social network is also consistent with previous research in this area. Krug and collaborators (2012) observed that children with an ED exhibited more solitary behaviour such as watching television and socialized less with friends. This was a common occurrence in our sample, who stated that they would often go to the cinema or watch films with their friends, rather than engaging in active socialising. Tiller and colleagues (1997) found that people with AN had a smaller social network than non-ED controls, which is supported by our study; however, as in Krug and collaborators' multicentre report, this study mainly focused on the current friendships of people with an ED rather than examining their friendships prior to the onset of the illness. Unfortunately, exploring this in detail was beyond the scope of the present study; however, investigating the changes and continuity in friendships during the onset and persistence of AN would be an interesting area to focus on in future research.

A somewhat surprising finding from our analysis was that three participants chose to speak of friendships which had dissolved rather than focusing on current friendships. This may be because their friendships became less important or prominent as their ED progressed, or it may be that the dissolution of these friendships impacted on the individual to such an extent that it remains a poignant issue which they wish to discuss. Geller, Zaitsoff and Srikameswaren (2002) found that basing self-worth on intimate friendships was associated with low self-esteem and greater body dissatisfaction in a group of adolescent females. Therefore if friendships dissolve, this may leave adolescents susceptible to developing an ED. This is an area which warrants further investigation.

The second most prevalent theme which emerged was lack of personal contact or communication with friends, which was present in six of the seven participants. Again, this did vary between participants, ranging from a vague description about not seeing their friends often to stating that they saw them a couple of times a month. The observation that some participants referred to their nominated "current" friendships in the past tense and focused on past rather than present friendships also suggests a lack of communication. The current literature regarding frequency of communication in individuals with ASD or an ED is lacking; though Krug and colleagues' (2012) study did find that as well as engaging in more solitary activities, people with an ED socialised less, which is consistent with the findings in our study. Additionally, there is some evidence in the literature which suggests that peer engagement in people with ASD reduces over the course of childhood (Rotherham-Fuller, Kasari, Chamberlain, \& Locke, 2010) and ASD friendships are characterised by less frequent get-togethers (Bauminger \& Shulman, 2003).

The reasons for infrequent contact with friends in the participants of this study, and in people with AN generally, are unclear. As in the case of their reduced social networks, it may be that the pressures of their ED prevent them from seeing their friends regularly or that hospitalisation and intensive treatment programmes mean that they are unable to spend time with their friends. Tiller and colleagues (1997) found that despite having less social support than controls, people with AN still perceived their support to be adequate; therefore they may not feel the need to have such frequent contact with friends as do people without an ED. An alternative explanation may be that people with AN find social situations difficult and therefore see their friends less frequently due to a lack of social skills, reflecting the difficulties experienced by people with ASD (Mazurek, 2013). On the other hand, if it is the case that people with AN feel lonely, particularly as a link has been reported between loneliness and ED pathology (Pritchard \& Yalch, 2009), then this could have implications for treatment outcome and re- 
covery. Unfortunately, the method of data collection used in our study was unable to capture whether the participants felt lonely or whether they perceived their social network and frequency of contact with friends to be adequate. Moreover, further research in this area is needed to determine whether these experiences reflect those of people with ASD.

Even when participants did have contact with their friends, a lot of this contact was electronic and therefore did not require the use of more complex interpersonal skills. The use of electronic communication by people with EDs is again under-researched, but may be suggestive of interpersonal communication difficulties. Clearly, in today's society, a lot of young people communicate via e-mails, text messages and social media websites; and it would be ludicrous to suggest that all adolescents suffer from socio-communicative deficits. In the context of interpersonal communication and EDs, however, it has been found that women with high levels of ED symptoms are less accurate at recognising happy and neutral facial expressions (Jones, Harmer, Cowen \& Cooper, 2008). Fear of, or difficulty in interpreting another person's emotional state may lead people with EDs to avoid face to face communication (Davies, Schmidt, Stahl, \& Tchanturia, 2011) and as a result show a preference for electronic communication. Difficulties in emotion recognition have also been observed in individuals with ASD, with a recent meta-analysis of 16 studies concluding that individuals with ASD have difficulties in the recognition of five out of the six universal emotions (Uljarevic \& Hamilton, 2013). Furthermore, when Oldershaw, Hambrook, Tchanturia, Treasure and Schmidt (2010) compared Emotional Theory of Mind (eToM) in people currently ill with AN and those who had recovered, they found that whilst eToM was significantly better in the recovered group, they still displayed some difficulty in recognising emotion in others. This suggests that the difficulty with emotion recognition experienced by people with AN is more likely to be a stable trait than to have arisen purely as a result of illness (though illness may indeed exacerbate this difficulty). Taken together with the aforementioned similar difficulties with emotion recognition observed in people with ASD, this could indicate a possible shared phenotype between the two disorders.

The theme of difficulty understanding the concept of friendship was found in four of the seven participants in this study and represents the most striking similarity to the ASD presentation. These participants found it difficult to describe what being a friend meant, often depicting their friends in terms of factual information or as being similar to them, and were unable to differentiate between a friend and an acquaintance. Clearly, these difficulties are unlikely to have arisen as a result of starvation in the participants; providing further support to the conjecture of a phenotypic similarity between individuals with AN and ASD. Carrington, Templeton and Papinczak (2003) described very similar difficulties in their sample of males with Asperger's syndrome, including a lack of insight into what constitutes friendship and finding it difficult to describe their friends. Participants in their study also appeared to find it easier to describe an acquaintance than a friend, again comparable to what was observed in our AN sample. However, to the best of our knowledge, no studies specifically exploring this theme in individuals with AN have yet been carried out.

The fourth and final theme identified was the tendency of three participants to focus attention away from themselves. This took the form of not being able to state what their friends may like about them, describing friendship in terms of the other's needs and discussing activities that their friends enjoy. A recent study by Zucker and collaborators (2014) attempted to categorise self-focused attention (SFA) in people with AN. They had predicted that due to the high weight and shape concern inherent in AN, SFA would be high in people currently suffering from the disorder. They found, however, that SFA was lowest in participants currently suffering from AN, when compared with healthy controls and people who had a history of AN but were weight-restored. Interestingly, a similar conclusion was formed by Lombardo and colleagues (2007) in their study with ASD participants; the researchers found that adults with ASD showed broad impairments in self-referential cognition, including impairments in SFA, when compared to non-ASD individuals.

This theme could also be interpreted in the context of low self-esteem, which is well-documented in the AN literature (Huon \& Brown, 1984; Silverstone, 1992; Fleming, Doris, \& Tchanturia, 2014); or as an absence of self-liking, which has been found to have a strong association with EDs (Silvera et al., 1998). A third possible explanation for this theme is increased alexithymia in AN patients, as discussed in the recent review by Nowakowski, McFarlane, and Cassin (2013), a component of which is the tendency to exhibit "externally-oriented thinking”. The emergence of this fourth theme seems somewhat at odds with the ASD literature, as individuals with ASD are often described as being more self-absorbed than other people as well as having difficulties with mentalizing (Frith, 1989). However, certainly low self-esteem has been demonstrated in individuals with ASD 
(Williamson, Craig, \& Slinger, 2008), and there have also been some studies showing an association between alexithymia and ASD; for example, Tani and colleagues (2004) found that individuals with Asperger's syndrome were significantly more alexithymic than healthy controls.

An alternative perspective on this theme is that it results from an inability to make inferences about others' mental states, or a failing in theory of mind (ToM). For example, it may be that the participants had difficulty in describing what their friends liked about them because they were unable to imagine how their friends might view them. A failing in ToM could potentially also explain why participants tended to describe friendship in terms of the other person's needs: because they were unable to perceive what their friends' views regarding the friendship needs of the participants themselves might be. Furthermore, this could explain why participants referred to taking part in shared activities that pleased their friends, as they were unable to conceive that their friends might consider shared activities that would please the participants themselves. Coupled with a failing in ToM, the presence of low self-esteem would explain why participants didn't simply describe their own needs or their own activity preferences. Considering the literature, the observation that individuals with ASD have difficulties employing ToM was first reported by Baron-Cohen, Leslie and Frith (1985) and is now a widely-recognised feature of ASD. However, there have also been a small number of studies which have found problems with ToM in individuals with AN, for example, Russell and colleagues (2009) and Tchanturia et al. (2004) found that adult patients with AN demonstrated significantly worse performance on two tasks which required effective ToM interpretation, when compared to non-ED controls. This latter finding, combined with our observations in the present study, represents a clear-cut similarity to the ASD presentation, and warrants further investigation.

This qualitative study highlighted problems with friendships before and during the onset of an ED using a semi-structured clinical interview. It provides some evidence that social difficulties in AN cannot purely be explained by the state of illness and chronic starvation. Nevertheless, our findings should be considered in light of the following limitations. Firstly, the patient group that took part in this study were adult females, who are generally expected to have more intimate, spontaneous and affectionate friendships than adult males (Booth, 1972; Maccoby \& Jacklin, 1974); and thus one should be cautious in judging the veracity of their responses as it is possible that expectations may have led to them either exaggerating the extent of their friendships or masking their friendship difficulties. A second limitation is that, given the semi-structured format of the ADOS, the participants' responses will, to some extent, have influenced the themes identified in the analysis. On a related front, the ADOS is not designed to foster an in-depth discussion of friendship issues, therefore precluding a more detailed exploration of the participants' friendship characteristics. A further limitation of this study is the small sample size of participants.

\section{Conclusion}

The aim of the present pilot study was to explore the friendship experiences of patients with a diagnosis of AN, who also present with ASD traits. The results of our thematic analysis suggest four principle themes: limited social network, lack of personal contact or communication, difficulty understanding the concept of friendship, and focus of attention away from the self; and the data suggest that these themes may have been relevant to our participants prior to the onset of their ED. The themes have been discussed in the context of other research into the friendship patterns of individuals with AN and ASD, and it would appear that not only are our findings in line with those of researchers working in the field of AN, but they are also reminiscent of the conclusions formed within the ASD literature. We therefore believe that our study lends further support to the hypothesised overlap between AN and ASD in a sub-group of cases, and has implications for both further research and clinical practice. With regards to further research, a larger scale study with a more in-depth analysis of the friendship patterns of individuals with AN and people with ASD is warranted, in order to better compare the experiences of these two groups. Considering clinical practice, efforts should be made to develop treatments which address friendship difficulties in AN, and to tailor current treatments in AN so that they address the needs of individuals who also exhibit ASD traits.

\section{Acknowledgments}

KT would like to thank the Maudsley Charity "Health in Mind" for their funding support and the clinical team at 
the Maudsley Eating Disorders Adult National Service.

\section{References}

Allison, C., Auyeung, B., \& Baron-Cohen, S. (2012). Toward Brief "Red Flags” for Autism Screening: The Short Autism Spectrum Quotient and the Short Quantitative Checklist in 1000 Cases and 3000 Controls. Journal of the American Academy of Child and Adolescent Psychiatry, 51, 202-212. http://dx.doi.org/10.1016/j.jaac.2011.11.003

American Psychiatric Association (2013). Diagnostic and Statistical Manual of Mental Disorders (5th ed.). Arlington, VA: American Psychiatric Publishing.

Baron-Cohen, S., Leslie, A. M., \& Frith, U. (1985). Does the Autistic Child Have a "Theory of Mind”? Cognition, 21, 37-46. http://dx.doi.org/10.1016/0010-0277(85)90022-8

Baron-Cohen, S., \& Wheelwright, S. (2003). The Friendship Questionnaire: An Investigation of Adults with Asperger Syndrome or High-Functioning Autism, and Normal Sex Differences. Journal of Autism and Developmental Disorders, 33, 509-517. http://dx.doi.org/10.1023/A:1025879411971

Bauminger, N., \& Kasari, C. (2000). Loneliness and Friendship in high-Functioning Children with Autism. Child Development, 71, 447-456. http://dx.doi.org/10.1111/1467-8624.00156

Bauminger, N., \& Shulman, C. (2003). The Development and Maintenance of Friendship in High-Functioning Children with Autism: Maternal Perception. Autism, 7, 81-97. http://dx.doi.org/10.1177/1362361303007001007

Bauminger, N., Solomon, M., Aviezer, A., Heung, K., Gazit, L., Brown, J., \& Rogers, S. J. (2008). Children with Autism and Their Friends: A Multidimensional Study of Friendship in High-Functioning Autism Spectrum Disorder. Journal of Abnormal Child Psychology, 36, 135-150. http://dx.doi.org/10.1007/s10802-007-9156-x

Booth, A. (1972). Sex and Social Participation. American Sociological Review, 37, 183-193. http://dx.doi.org/10.2307/2094026

Braun, V., \& Clarke, V. (2006). Using Thematic Analysis in Psychology. Qualitative Research in Psychology, 3, 77-101. http://dx.doi.org/10.1191/1478088706qp063oa

Carrington, S., Templeton, E., \& Papinczak, T. (2003). Adolescents with Asperger Syndrome and Perceptions of Friendship. Focus on Autism and other Developmental Disabilities, 18, 211-218. http://dx.doi.org/10.1177/10883576030180040201

Davies, H., Schmidt, U., Stahl, D., \& Tchanturia, K. (2011). Evoked Facial Emotional Expression and Emotional Experience in People with Anorexia Nervosa. International Journal of Eating Disorders, 44, 531-539. http://dx.doi.org/10.1002/eat.20852

Davies, H., Schmidt, U., \& Tchanturia, K. (2013). Emotional Facial Expression in Women Recovered from Anorexia Nervosa. BMC Psychiatry, 13, 291. http://dx.doi.org/10.1186/1471-244X-13-291

Davies, S. (2004). A Group-Work Approach to Addressing Friendship Issues in the Treatment of Adolescents with Eating Disorders. Clinical Child Psychology and Psychiatry, 9, 519-531. http://dx.doi.org/10.1177/1359104504046157

Fairburn, C. G., Cooper, Z., Doll, H. A., \& Welch, S. L. (1999). Risk Factors for Anorexia Nervosa: Three Integrated Case-Control Comparisons. JAMA Psychiatry, 56, 468-476. http://dx.doi.org/10.1001/archpsyc.56.5.468

Fleming, C., Doris, E., \& Tchanturia, K. (2014). Self-Esteem Group Work for Inpatients with Anorexia Nervosa. Advances in Eating Disorders: Theory, Research and Practice. http://dx.doi.org/10.1080/21662630.2014.888956

Flora, C. (2013). Friendfluence: The Surprising Ways Friends Make Us Who We Are. New York: Random House Inc., Doubleday.

Frith, U. (1989). Autism: Explaining the Enigma. Oxford: Blackwell Publishing.

Geller, J., Zaitsoff, S. L., \& Srikameswaran, S. (2002). Beyond Shape and Weight: Exploring the Relationship between Non-Body Determinants of Self-Esteem and Eating Disorder Symptoms in Adolescent Females. International Journal of Eating Disorders, 32, 344-351. http://dx.doi.org/10.1002/eat.10083

Gillberg, C. (1985). Autism and Anorexia Nervosa: Related Conditions? Nordic Journal of Psychiatry, 39, 307-312. http://dx.doi.org/10.3109/08039488509101911

Gillberg, C., \& Rastam, M. (1992). Do Some Cases of Anorexia Nervosa Reflect Underlying Autistic-Like Conditions? Behavioural Neurology, 5, 27-32. http://dx.doi.org/10.1155/1992/259318

Hambrook, D., Brown, G., \& Tchanturia, K. (2012). Emotional Intelligence in Anorexia Nervosa: Is Anxiety a Missing Piece of the Puzzle? Psychiatry Research, 200, 12-19. http://dx.doi.org/10.1016/j.psychres.2012.05.017

Hambook, D., Tchanturia, K., Schmidt, U., Russell, T., \& Treasure, J. (2008). Empathy, Systemizing, and Autistic Traits in Anorexia Nervosa: A Pilot Study. British Journal of Clinical Psychology, 47, 335-339.

http://dx.doi.org/10.1348/014466507X272475 
Harrison, A., Mountford, V., \& Tchanturia, K. (2014). Social Anhedonia and Work and Social Functioning in the Acute and Recovered Phases of Eating Disorders. Psychiatry Research, 218, 187-194. http://dx.doi.org/10.1016/j.psychres.2014.04.007

Harrison, A., Sullivan, S., Tchanturia, K., \& Treasure, J. (2010). Emotional Functioning in Eating Disorders: Attentional Bias, Emotion Recognition and Emotion Regulation. Psychological Medicine, 40, 1887-1897. http://dx.doi.org/10.1017/S0033291710000036

Harney, M. B., Fitzsimmons-Craft, E. E., Maldonado, C. R., \& Bardone-Cone, A. M. (2014). Negative Affective Experiences in Relation to Stages of Eating Disorder Recovery. Eating Behaviors, 15, 24-30. http://dx.doi.org/10.1016/j.eatbeh.2013.10.016

Huke, V., Turk, J., Saeidi, S., Kent, A., \& Morgan, J. F. (2013). Autism Spectrum Disorders in Eating Disorder Populations: A Systematic Review. European Eating Disorders Review, 21, 345-351. http://dx.doi.org/10.1002/erv.2244

Huon, G., \& Brown, L. B. (1984). Psychological Correlates of Weight Control among Anorexia Nervosa Patients and Normal Girls. British Journal of Medical Psychology, 57, 61-66.

Krug, I., Penelo, E., Fernandez-Aranda, F., Anderluh, M., Bellodi, L., Cellini, E., Bernardo, M., Granero, R., Karwautz, A., Nacmias, B., Ricca, V., Sorbi, S., Tchanturia, K., Wagner, G., Collier, D., \& Treasure, J. (2012). Low Social Interactions in Eating Disorder Patients in Childhood and Adulthood: A Multi-Centre European Case Control Study. Journal of Health Psychology, 18, 26-37. http://dx.doi.org/10.1177/1359105311435946

Kuo, M. H., Orsmond, G. I., Cohn, E. S., \& Coster, W. J. (2011). Friendship Characteristics and Activity Patterns of Adolescents with an Autism Spectrum Disorder. Autism, 17, 481-500. http://dx.doi.org/10.1177/1362361311416380

Jackson, T., Weiss, K. E., Lunquist, J. J., \& Soderlind, A. (2005). Sociotrophy and Perceptions of Interpersonal Relationships as Predictors of Eating Disturbances among College Women: Two Prospective Studies. The Journal of Genetic Psychology: Research and Theory on Human Development, 166, 346-360. http://dx.doi.org/10.3200/GNTP.166.3.346-360

Jones, L., Harmer, C., Cowen, P., \& Cooper, M. (2008). Emotional Face Processing in Women with High and Low Levels of Eating Disorder Related Symptoms. Eating Behaviors, 9, 389-397. http://dx.doi.org/10.1016/j.eatbeh.2008.03.001

Lang, K., Lopez, C., Stahl, D., Tchanturia, K., \& Treasure, J. (2014). Central Coherence in Eating Disorders: An Updated Systematic Review and Meta-Analysis. World Journal of Biological Psychiatry, 1, 1-13. http://dx.doi.org/10.3109/15622975.2014.909606

Larson, R., \& Verma, S. (1999). How Children and Adolescents Spend Time across the World: Work, Play and Developmental Opportunities. Psychological Bulletin, 125, 701-736. http://dx.doi.org/10.1037/0033-2909.125.6.701

Lombardo, M. V., Barnes, J. L., Wheelwright, S. J., \& Baron-Cohen, S. (2007). Self-Referential Cognition and Empathy in Autism. PloS ONE, 9, Article ID: e883. http://dx.doi.org/10.1371/journal.pone.0000883

Lord, C., Risi, S., Lambrecht, L., Cook, E. H., Leventhal, B. L., DiLavore, P. C., Pickles, A., \& Rutter, M. (2000). The Autism Diagnostic Observation Schedule-Generic: A Standard Measure of Social and Communication Deficits Associated with the Spectrum of Autism. Journal of Autism and Developmental Disorders, 30, 205-223. http://dx.doi.org/10.1023/A:1005592401947

Maccoby, E. E., \& Jacklin, C. N. (1974). The Psychology of Sex Differences. Stanford, CA: Stanford University Press.

Mazurek, M. O. (2013). Loneliness, Friendship and Well-Being in Adults with Autism Spectrum Disorders. Autism, 1-10.

Morris, R., Bramham, J., Smith, E., \& Tchanturia, K. (2014). Empathy and Social Functioning in Anorexia Nervosa before and after Recovery. Cognitive Neuropsychiatry, 19, 47-57. http://dx.doi.org/10.1080/13546805.2013.794723

Nowakowski, M. E., McFarlane, T., \& Cassin, S. (2013). Alexithymia and Eating Disorders: A Critical Review of the Literature. Journal of Eating Disorders, 1, 21. http://dx.doi.org/10.1186/2050-2974-1-21

Oldershaw, A., Hambrook, D., Tchanturia, K., Treasure, J., \& Schmidt, U. (2010). Emotional Theory of Mind and Emotional Awareness in Recovered Anorexia Nervosa Patients. Psychosomatic Medicine, 72, 73-79. http://dx.doi.org/10.1097/PSY.0b013e3181c6c7ca

Oldershaw, A., Treasure, J., Hambrook, D., Tchanturia, K., \& Schmidt, U. (2011). Is Anorexia Nervosa a Version of Autism Spectrum Disorders? European Eating Disorders Review, 19, 462-474. http://dx.doi.org/10.1002/erv.1069

Orsmond, G. I., Krauss, M. W., \& Seltzer, M. M. (2004). Peer Relationships and Social and Recreational Activities among Adolescents and Adults with Autism. Journal of Autism and Developmental Disorders, 34, 245-256. http://dx.doi.org/10.1023/B:JADD.0000029547.96610.df

Pritchard, M. E., \& Yalch, K. L. (2009). Relationships among Loneliness, Interpersonal Dependency and Disordered Eating in Young Adults. Personality and Individual Differences, 46, 341-346. http://dx.doi.org/10.1016/j.paid.2008.10.027

Rotheram-Fuller, E., Kasari, C., Chamberlain, B., \& Locke, J. (2010). Social Involvement of Children with Autism Spectrum Disorders in Elementary School Classrooms. Journal of Child Psychology and Psychiatry, 51, 1227-1234. http://dx.doi.org/10.1111/j.1469-7610.2010.02289.x 
Russell, T. A., Schmidt, U., Doherty, L., Young, V., \& Tchanturia, K. (2009). Aspects of Social Cognition in Anorexia Nervosa: Affective and Cognitive Theory of Mind. Psychiatry Research, 168, 181-185.

http://dx.doi.org/10.1016/j.psychres.2008.10.028

Silvera, D. H., Bergensen, T. D., Bjorgum, L., Perry, J. A., Rosenvinge, J. H., \& Holte, A. (1998). Analysing the Relation between Self-Esteem and Eating Disorders: Differential Effects of Self-Liking and Self-Competence. Eating and Weight Disorders, 3, 95-99. http://dx.doi.org/10.1007/BF03339995

Silverstone, P. H. (1992). Is Chronic Low Self-Esteem the Cause of Eating Disorders? Medical Hypotheses, 39, $311-315$. http://dx.doi.org/10.1016/0306-9877(92)90054-G

Tani, P., Lindberg, N., Joukamaa, M., Nieminen-von Wendt, T., von Wendt, L., Appelberg, B. et al. (2004). Asperger Syndrome, Alexithymia and Perception of Sleep. Neuropsychobiology, 49, 64-70. http://dx.doi.org/10.1159/000076412

Tchanturia, K., Davies, H., Harrison, A., Fox, J., Treasure, J., \& Schmidt, U. (2012). Altered Social Hedonic Processing in Eating Disorders. International Journal of Eating Disorders, 45, 962-969. http://dx.doi.org/10.1002/eat.22032

Tchanturia, K., Davies, H., Harrison, A., Roberts, M., Nakazato, M., Schmidt, U., Treasure, J., \& Morris, R. (2012). Poor Cognitive Flexibility in Eating Disorders: Examining the Evidence Using the Wisconcin Cart Sorting Task. PLoS ONE, 7, Article ID: e28331. http://dx.doi.org/10.1371/journal.pone.0028331

Tchanturia, K., Hambrook, D., Curtis, H., Jones, T., Lounes, N., Fenn, K., Keys, A., Stivenson, L., \& Davies, H. (2013). Work and Social Adjustment in Patients with Anorexia Nervosa. Comprehensive Psychiatry, 54, 41-45. http://dx.doi.org/10.1016/j.comppsych.2012.03.014

Tchanturia, K., Happe, F., Godley, J., Treasure, J., Bara-Carril, N., \& Schmidt, U. (2004). “Theory of Mind” in Anorexia Nervosa. European Eating Disorders Review, 12, 361-366. http://dx.doi.org/10.1002/erv.608

Tchanturia, K., Lloyd, S., \& Lang, K. (2013). Cognitive Remediation Therapy for Anorexia Nervosa: Current Evidence and Future Research Directions. International Journal of Eating Disorders, 46, 492-495. http://dx.doi.org/10.1002/eat.22106

Tchanturia, K., Smith, E., Weineck, F., Fidanboylu, E., Kern, N., Treasure, J., \& Baron-Cohen, S. (2013). Exploring Autistic Traits in Anorexia: A Clinical Study. Molecular Autism, 4, 44. http://dx.doi.org/10.1186/2040-2392-4-44

Tiller, J. M., Sloane, G., Schmidt, U., Troop, N., Power, M., \& Treasure, J. L. (1997). Social Support in Patients with Anorexia Nervosa and Bulimia Nervosa. International Journal of Eating Disorders, 21, 31-38. http://dx.doi.org/10.1002/(SICI)1098-108X(199701)21:1<31::AID-EAT4>3.0.CO;2-4

Troop, N. A., \& Bifulco, A. (2002). Childhood Social Arena and Cognitive Sets in Eating Disorders. British Journal of Clinical Psychology, 41, 205-211. http://dx.doi.org/10.1348/014466502163976

Uljarevic, M., \& Hamilton, A. (2013). Recognition of Emotions in Autism: A Formal Meta-Analysis. Journal of Autism and Developmental Disorders, 43, 1517-1526. http://dx.doi.org/10.1007/s10803-012-1695-5

Williamson, S., Craig, J., \& Slinger, R. (2008). Exploring the Relationship between Measures of Self-Esteem and Psychological Adjustment among Adolescents with Asperger Syndrome. Autism, 12, 391-402. http://dx.doi.org/10.1177/1362361308091652

Wilkinson, R. G., \& Marmot, M. G. (2003). Social Determinants of Health: The Solid Facts. Copenhagen: World Health Organisation.

Zucker, N., Wagner, H. R., Merwin, R., Bullik, C. M., Moskovich, A., Keeling, L., \& Hoyle, R. (2014). Self-Focused Attention in Anorexia Nervosa. International Journal of Eating Disorders, Early View. http://dx.doi.org/10.1002/eat.22307 
Scientific Research Publishing (SCIRP) is one of the largest Open Access journal publishers. It is currently publishing more than 200 open access, online, peer-reviewed journals covering a wide range of academic disciplines. SCIRP serves the worldwide academic communities and contributes to the progress and application of science with its publication.

Other selected journals from SCIRP are listed as below. Submit your manuscript to us via either submit@scirp.org or Online Submission Portal.
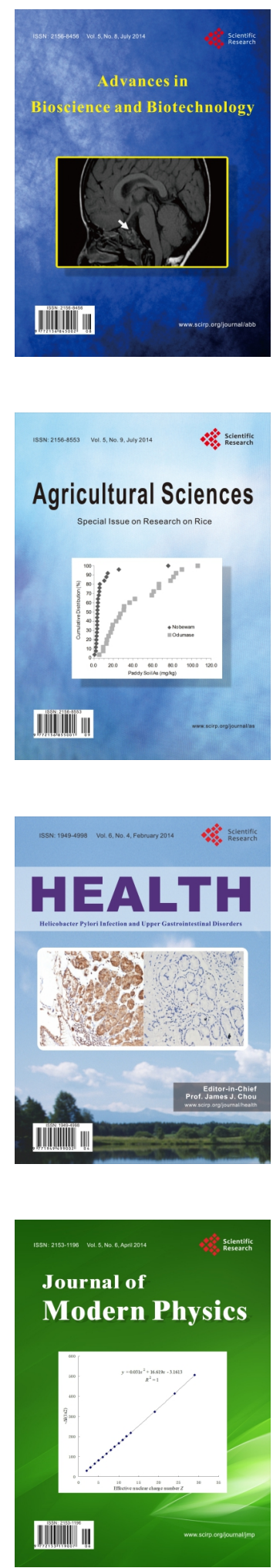
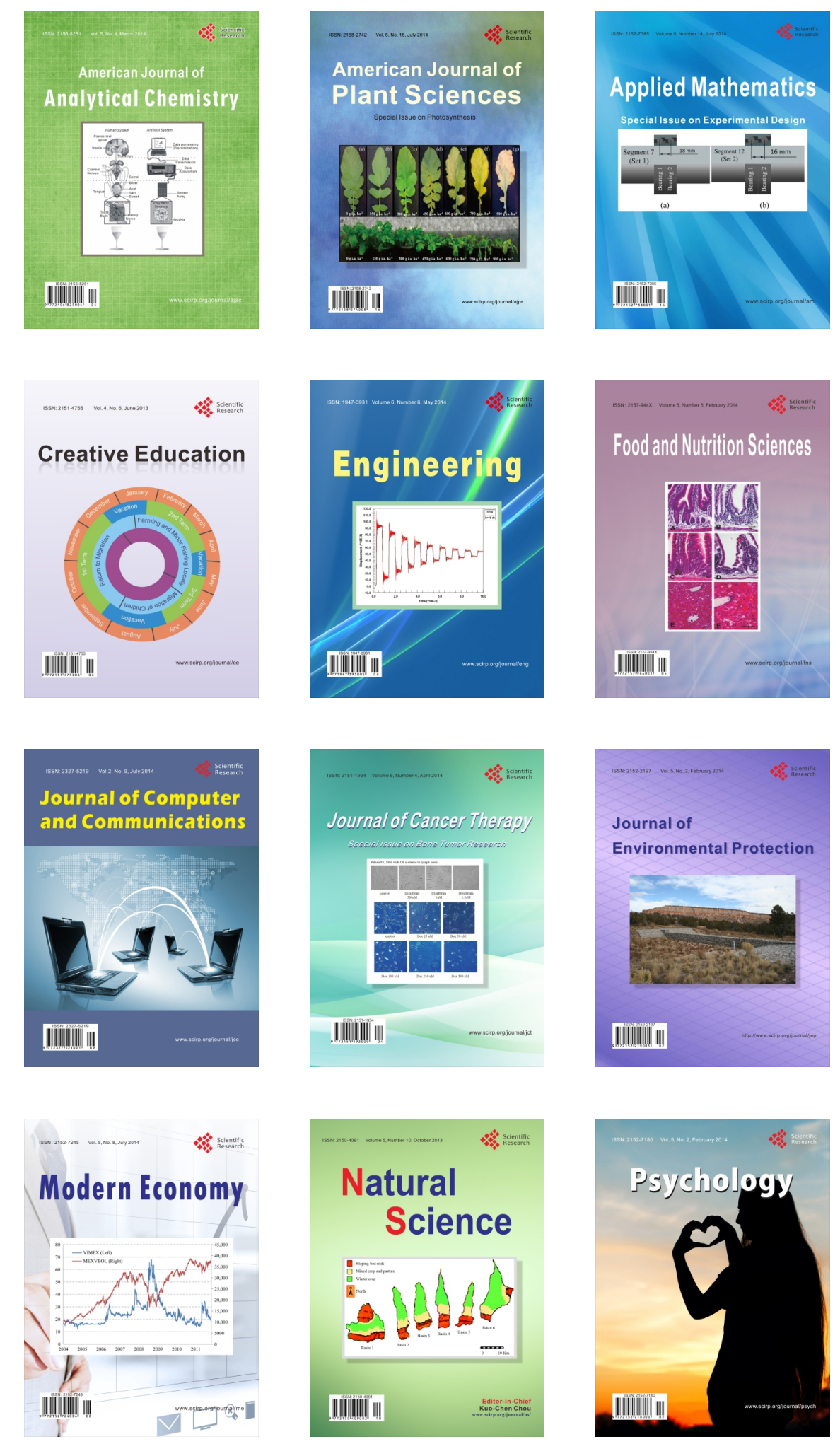